\title{
Lexical Errors of Third Year Undergraduate Students
}

\author{
Wafa Ismail Saud ${ }^{1}$ \\ ${ }^{1}$ Faculty of Languages and Translation, King Khalid University, Abha, Saudi Arabia \\ Correspondence: Wafa Ismail Saud, Faculty of Languages and Translation, King Khalid University, Abha, Saudi \\ Arabia. E-mail: wesaud@kku.edu.sa
}

Received: September 23, 2018 Accepted: October 24, 2018 Online Published: October 26, 2018

doi: $10.5539 /$ elt.v11n11p161

URL: http://doi.org/10.5539/elt.v11n11p161

\begin{abstract}
The aim of the study was to examine the lexical errors made by EFL students. The technique for eliciting information employed was an achievement test. A sample of 30 Saudi female students was asked to write essays in English that were assessed by the researcher. The students were all majoring in English in the third year at King Khalid University. James (1998) taxonomy was selected as the most comprehensive framework for the analysis of the lexical errors in the students' writing. A total of 137 lexical errors were identified and analysed. These errors were divided into formal 117 (85.40) and semantic 20 (14.60). Formal mis- selection 54 (39.42) was the most frequent major category of lexical formal errors while mis-formation 15 (10.95) was the least frequent one. Confusion of sense relations 14 (10.22) was the most frequent among lexical semantic errors. At the individual level of lexical formal errors, the most problematic words for students were the vowel based types 24 (17.52) and borrowing and blending were not problematic at all. At the individual level of lexical semantic errors, the most problematic words for students were near synonyms 8 (5.84) and the least problematic words were general terms for specific ones and overtly specific terms 1 (0.73).Pedagogical implications for teaching vocabulary to EFL learners and recommendations for areas for further research were suggested.
\end{abstract}

Keywords: lexical errors, formal errors, semantic errors, formal mis-selection, mis-formation, distortion, sense relation errors, collocation errors, vocabulary

\section{Introduction}

Lexical knowledge is one of the essential components in language learning. Limited vocabulary and wrong choice of lexical items are major obstacles in successful communication. Schmitt (2000) states that "Lexical knowledge is central to communicative competence and to the acquisition of the second language" (p. 55). In addition, Folse (2004) states that, "with poor vocabulary, communication is constraint considerably. You can get by without grammar; you cannot get by without vocabulary" (p. 2).

Investigating lexical errors helps teachers to be aware of the source of these errors and address them in class. James (1998) developed a lexical error taxonomy that consists of two major categories, formal and semantic. The formal errors are classified into 3 major categories which in turn are divided into 12 subcategories. On the other hand, the semantic errors are divided into 2 major categories which are in turn subdivided into 4 subcategories.

James's lexical error taxonomy is explained below:

I). Lexical formal errors: They are made because of three reasons:

1). Formal mis-selection: It includes confusion in the selection of target language suffix type, prefix type, vowelbased type and consonant-based type.

2). Mis-formation: This involves the wrong word formation that includes borrowing from L1, coinage, i.e. creating non existing L2 word, and calque, i.e. translating a word from L1 words.

3). Distortions: They are caused as a result of misapplication of the target language. They involve omission (i.e letter omission from a word), over-inculsion, (i.e. addition of some letters within a word), mis-selection, (i.e. wrong choice of two similar letters), mis-ordering, (i.e. wrong ordering of letters within a word), and finally blending, (i.e. an error of fusing two items together during the production of words).

II). Semantic errors are two types: First, confusion of sense relations, which are the result of using a superonym for a hyponym, or using a hyponymy for a superonym, using inappropriate co-hyponyms, and finally using a 
wrong near synonym. Second, collocational errors, which are caused as a result of wrong association of two words.

\subsection{Statement of the Problem}

Lexical knowledge is essential for mastery of the language. It helps learners convey meaning, and it should be selected accurately and properly. Unlike syntactic and phonological errors, lexical errors are less tolerated as they hinder communication.

However, from the personal teaching experience of the author at King Khalid University, it is clear that despite two courses students study in vocabulary buildings, still they are not sufficiently proficient in using vocabulary, and they continue to produce many lexical errors. The problem could be attributed to the fact that students memorise words in lists more than using them in context. Much attention should be paid to develop students' vocabulary and achieve competence.

\subsection{Objectives}

This study was conducted with the purpose of identifying the lexical errors made by third year undergraduate students to help teachers be aware of them and address them in their teaching.

\subsection{Research Question}

In meeting the objectives, the study intends to answer the following question:

What are the types of lexical errors made by third year undergraduate students at both individual and category levels?

\subsection{Significance of the Study}

Carter (1998) states that lexical errors cannot be tolerated as they could hinder communication. Analysis of students' lexical errors, and diagnosing areas of their lexical difficulties, and gaining insight into the types of errors they make, could help teachers take actions needed to help their students progress in learning English. It could help pave the way for preparation of better course materials, and help upgrade teaching and learning processes to best suit the learners. It could help competent learners achieve their potential, and help less capable ones improve their vocabulary. The findings of this study would make a valuable contribution in the field of lexical errors in the foreign language context, especially for Arab and Saudi students.

\section{Literature Review}

Lexical error analysis is an important concern among English teachers and researchers. It has generated considerable attention and research as a means of identifying students' needs and progress in L2 acquisition. There is a growing number of studies that deal with the lexical difficulties English language learners face.

Among the studies that had been concerned with lexical error analysis in EFL and ESL contexts was the study of Hemchua and Schmitt (2006). They analysed the lexical errors in English compositions of Thai learners. The participants were 20 Thai third-year English majors at a university in Bangkok. Students were asked to write a composition about the advantages of urban or country living. Their compositions were analysed and lexical errors were categorized based on James' (1998) taxonomy, with some addition from Leech's semantics (1981). The findings indicated that the most problematic area for students was semantics more than the forms of words. Other findings showed that the most frequent category of formal errors was the formal mis-selection of words followed by distortions. On the other hand, the most frequent category of semantic errors was collocation errors, followed by confusion of sense relation errors.

Similarly, Shalaby, Yahya and El-Komi (2009) examined the types of lexical errors in the writing of Saudi college students. The subjects of the study were 96 female students studying English in the preparatory year at Taibah University, Madina, Saudi Arabia. Hemchua and Schmitt's (2006) taxonomy was used to analyse their lexical errors. Results revealed that lexical semantic errors were more frequent than lexical formal errors. The most problematic error category they found was in the mis-selection of suffix type. Lexical errors of L1 direct translation was next in frequency. The most frequent category of lexical semantic errors was the confusion of sense relations, followed by collocation errors.

Rajab, Darus, and Aladdin (2016) investigated some semantic interlingual errors produced by Libyan postgraduate students. The subjects were male and female students at Malysian universities. 26 essays were analysed. Errors were classified into five categories namely, formal mis-selection, formal mis-formation, lexical choice, collocation and lexico-grammatical choice. The results showed that in direct translation from L1, assumed synonymy, and mis-selection of letters, had the highest frequency of errors. 
Al-Shormani and Al-Sohbani (2012) aimed to describe the semantic errors in 30 essays produced by level three undergraduate students at a Yemeni university. The semantic errors were categorized into lexical, collocation, and lexico-grammatical ones. Each category was further classified into other subcategories. The findings indicated that formal mis-formation category recorded the highest score for Yemeni undergraduate students, while formal mis-selection, and specifically, the mis-selection of prefix type, recorded the least score. Regarding the source of errors, it was found that L1 interference, and the insufficient knowledge of English, played a great part in that.

Hamadi (2016) investigated the lexical errors in English compositions of EFL Tunisian learners. The participants were 20 third year undergraduate students at ISEAH Institute of Kef, Tunisia. James' lexical error taxonomy was used in the analysis of errors. The findings showed that lexical formal errors were more frequent than lexical semantic ones in the writing of Tunisian EFL learners. Another finding was that the category of distortion was the most problematic one, followed by mis-formation, and the least problematic was formal mis-selection.

Basir, Abdullah and Zaiyadi (2015) conducted a study on lexical errors of diploma-level students from an English for Academic purposes classroom. 19 students participated in the study. Lexical errors were identified and categorized. The findings indicated that students used 3 categories most frequently, they were; wrong word choice, omission and misspelling. On the other hand, redundancy, word formation and collocation were used the lease frequently.

\section{Methodology}

\subsection{Research Design}

Quantitative research was conducted to describe the lexical errors made by EFL students. Descriptive statics were employed such as frequencies and mean scores.

\subsection{Participants}

The participants in this study were 30 Saudi female undergraduate students from the English department, King Khalid University, Saudi Arabia. They were third year students in the academic year 2017-2018. Their ages ranged between 18-20 years.

\subsection{Data Collection Procedures}

An achievement test was administered to the 30 students to investigate the lexical errors they made. They were asked to write a composition of about 200 words. The topic of the composition was "describe your university". They were given thirty minutes to complete the task. James (1998) taxonomy was selected as the most comprehensive for the analysis of the lexical errors in the students' writing. Descriptive statistical procedures were employed for data analysis such as frequencies and mean scores.

\section{Results and Discussions}

Following is a discussion, with some examples, of the lexical errors made by the students in their writing. The discussion aims at highlighting the type of errors they made, and analysing them in terms of the frequency of their occurrence. Analysis of the data obtained from the 30 compositions indicated that EFL students in this study made a total of 137 lexical errors. These errors were divided into two types, formal 117 (85.40\%), and semantic $20(14.60 \%)$. Table 1 lists the lexical errors used by EFL undergraduate students, their types, Frequencies and mean scores.

Table 1. Frequency and mean score of lexical formal and semantic errors

\begin{tabular}{lll}
\hline Error Type & Frequency & Mean Score \\
\hline Lexical Formal Errors & 117 & 85.40 \\
Lexical Semantic Errors & 20 & 14.60 \\
Total & 137 & 100.0 \\
\hline
\end{tabular}

Table 1 above shows that EFL undergraduate third year students face difficulties with lexical formal errors more than semantic ones. This finding was consistent with the results obtained from the study of Hamadi (2016). The reason for the formal errors could probably be their inadequate understanding and acquisition of vocabulary. 


\subsection{Lexical Formal Errors}

Descriptive statistical analysis of the data obtained is summarized in Table 2. It illustrates the variation in the frequencies of errors at the individual and category levels.

Table 2. Frequency and mean score of lexical formal errors

\begin{tabular}{llll}
\hline Descriptive Statistics & & \\
\hline No. & Error Types & Frequency & Mean Score \\
\hline 1 & Formal Mis-selection & 54 & 39.42 \\
1.1 & Suffix type & 22 & 16.06 \\
1.2 & Prefix type & 1 & 0.73 \\
1.3 & Vowel-based type & 24 & 17.52 \\
1.4 & Consonant-based type & 7 & 5.12 \\
2 & Mis-formation & 15 & 10.95 \\
2.1 & Borrowing & 0 & 0.0 \\
2.2 & Coinage & 4 & 2.92 \\
2.3 & Calque & 11 & 8.03 \\
3 & Distortions & 48 & 35.04 \\
3.1 & Omission & 17 & 12.41 \\
3.2 & Over-inclusion & 12 & 8.76 \\
3.3 & Mis-selection & 17 & 12.41 \\
3.4 & Mis-ordering & 2 & 1.46 \\
3.5 & Blending & 0 & 0.0 \\
\hline
\end{tabular}

Table 2 above shows that the most frequent major category of lexical formal errors made by undergraduate third year students was forma mis-selection 54 (39.24), followed by distortions 48 (35.04). The least major category errors made by the students was misformation15 (10.95). Similar results have been reported in a study by Shalaby, Yahya and El-Komi (2009) which stated that students errors in formal mis-selection was the highest in frequency. The findings, however, contradict with that of Al-Shormani and Al-Sohbani (2012) which reported that the least problematic area was the formal mis-selection and the most problematic area was the formal mis-formation.

At the individual level, the most problematic words for students were the vowel based types 24 (17.52). That was followed by suffix type 22 (16.06), and then by omission, which had the same frequency as mis-selection 17 (12.41). Next was over-inclusion 12 (8.76), and then calque 11 (8.03). Then consonant based type 7 (5.12). The least problematic were coinage 4 (2.92), then mis-ordering 2 (1.46) and finally prefix type $1(0.73)$. Borrowing and blending $0(0.0)$ were not problematic at all.

\subsection{Examples of Lexical Formal Errors}

1). Results showed that students misspelled the vowels, and this is probably due to inadequate learning and practice, besides there is an inherent difficulty in English as many English words are not spelled as they are spoken. Their L1 also does not include all the vowels used in the English language. The following are some examples of this type of errors.

dipartments (department), nigative (negative), discribe (describe), compus (campus), wolk (wake), hapet (habit), lestien (listen), theise (these), caffee (coffee), secrtiries (secretieries), becose (because), hear (here), deen (dean), prey (pray), Aribic (Arabic), ruels (rules), rued (rude).

Teachers could help their students by developing some conscious raising activities for them on the use of vowels. They could also help them by using tongue twisters and song games to practice saying certain sounds. Teachers could encourage their students to listen to online dictionary pronunciation of words, and encourage them to repeat them with the audio. 
2). Students showed confusion in the use of suffixes. They failed to select the appropriate suffixes to form correct words to express themselves in certain contexts. The following examples illustrate the issue:

I have many responsible (responsibilities).

There are many room (rooms).

The build (building) was big.

I like all subjects special (especially) English.

I studying (study) at KKU.

I feeling (feel) happy.

The improving (improvement) is fast.

I can reading (read).

I am interesting (interested) in learning English.

Students need more training on the morphological structure of words. Teachers could develop activities to help their students master words with suffixes, such as matching suffixes to root words activity, or fill in the suffix activity.

3). Students omitted some letters, either consonants or vowels. The source of these errors was L2 omission. Errors are exemplified in the following words.

secrtries (secretaries), univrsity (university), acadmic (academic), phontics (phonetics), completly (completely), discrib (describe), colleg (college), exllent (excellent), intrest (interest), resturant (restaurant), chire (chair), ther (their), contries (countries), ofices (offices).

It is recommended that students are encouraged to practice writing words out by hand and read more. Writing helps students internalise the correct order of the letters. Reading helps students see the words spelled correctly.

4). Students mis-selected some letters. The cause of this type of error may refer to the English spelling problems. Some English letters may represent more than one different sounds, or the same sound can be represented by many different letters. Examples of mis-selection errors are as follows:

univercity (university), axcent (accent), spesific (specific), fase (face), juese (juice), tence (tense).

5). Students made some over-inclusion errors as a result of over-generalizing an existing rule in L2. Examples of these errors are as follows:

Possitive (positive), fieleds (fields), understande (understand), quize (quiz), wolk (wake), wright (right), frome (from), croweded (crowded), liberary (library).

6). Students made some calque errors. These errors are committed as a result of literal translation of L1 word (James, 1998). Examples of calque errors are as follows:

It is not from (It is not) the opinion of the students.

The exam is not comfortable (easy).

We do not have a mixture (co-education) of boys and girls in our university.

It becomes have (has).

It is one from (of) the modern universities.

It (is) very crowded.

The center (is) in Abha.

In the center (there is) a big yard.

The examples above show that students think in Arabic, and their choice of words is a clear example of translating from Arabic into English. Students need much more exposure to the target language and much more practice to help them get used to thinking and using L2 native-like expressions.

7). Students made some consonant-based errors in which they fail to select the correct consonants. According to James (1998) the source of these errors is L1. Examples of this type are as follows:

ruper (rubber), hapet (habit), apsent (absent), bronounciation (pronunciation), broblem (proplem).

In dealing with this type of errors, it is suggested that teachers focus on developing exercises that distinguish 
between minimal pairs. Doing so would help students feel the differences better, and help them to overcome the problem of mis-selection of consonants and vowels.

8). Students made some errors in coining words. These errors show that learners are active thinkers; they find ways to communicate. Examples of this type of error are as follows:

Take a cycle (take a round).

Tooth doctor (dentist).

I asked her to call me again (call back).

9). Students mis-ordered some words. Mis-ordering can be for letters or for words. Mis-ordering errors are exemplified below:

The mark will be full (the full mark).

Teacher English (English teacher).

\subsection{Examples of Lexical Semantic Errors}

Descriptive statistical analysis of the data obtained is summarized in Table 3. It illustrates the variation in the frequencies of errors at the individual and category level.

Table 3. Frequency and mean score of lexical semantic errors

\begin{tabular}{llll}
\hline \multicolumn{2}{l}{ Descriptive Statistics } & & \\
\hline No & Error Types & Frequency & Mean Score \\
\hline 1 & Confusion of sense relations & 14 & 10.22 \\
1.1 & General term for specific one & 1 & 0.73 \\
1.2 & Overtly specific term & 1 & 0.73 \\
1.3 & Inappropriate co-hyponymy & 4 & 2.92 \\
1.4 & Near synonyms & 8 & 5.84 \\
2 & Collocation errors & 6 & 4.38 \\
\hline
\end{tabular}

Table 3 above shows that the most frequent major category of lexical semantic errors made by undergraduate third year students was confusion of sense relation 14 (10.22) followed by collocation errors 6 (4.38). This finding is in harmony with the results of the study by Shalaby, Yahya and El-Komi (2009) which revealed that confusion of sense relation was the most frequent category of lexical semantic errors.

At the individual level, the most problematic words for students were near synonyms 8 (5.84) followed by collocations 6 (4.38), then by co-hyponymy 4 (2.92). The least problematic were general term for specific one, and overtly specific term $1(0.73)$

\subsection{Lexical Semantic Errors}

The following are examples of lexical semantic errors with the correction in brackets:

1) Results showed that students made errors in near synonyms such as:

The teacher does not reply (answer) us.

The university is beautiful (a nice place).

The basic (main) building.

She will back (return).

I will get work (a job) after I graduate.

2) Students made errors in collocation. These errors had a negative impact on the students' communicative competence. Examples of of collocation errors are as follows:

I will make (do) the assignment.

We repeat again (repeat) after the teacher. 
When I finish my grade (study).

Teachers could help their students learn correct collocations by encouraging them to memorize chunks of words. They may also raise their students' awareness of using linguistic software available to them.

3). Students made errors in the choice of co-hyponymy such as:

The doctors (professors) at the university.

My old (age) is twenty years.

Multistudying (different fields).

Sub college (branches of the college).

In sum, the findings indicated that the students made several types of lexical errors writing in English. The vast majority of their errors were lexical formal ones. The subcategories of lexical formal and semantic errors varied in their frequency of occurrence. Two subcategories occurred most frequently which were vowel-based type, and suffix type. Three subcategories occurred least frequently, prefix type, general term for specific one, and overtly specific term. Finally two errors did not occur at all which were borrowing and blending.

\section{Conclusion and Recommendation}

The results indicated that students' fell in many types of lexical formal and semantic errors. Those errors may be due to insufficient practice, or to the inadequacy of the amount of knowledge they receive. They did not have enough vocabulary to express themselves accurately. Instructors could help them by designing activities for areas that need improvement. It is also recommended that instructors give more emphasis on spelling practices, selecting suitable suffixes, and on near synonyms, and collocation. Such activities could help them master their vocabulary. There also is a need to teach vocabulary in context rather than teaching them in isolated lists. Teachers could provide their students with feedback on their mistakes and emphasize their correction, in a non-threatening way, in order to raise their learners' awareness and ability to correct themselves. Teachers know the role of interference of their students first language in the acquisition of a second language; so they could help their students differentiate between the lexises of the Arabic and English languages. It is also recommended to conduct more studies on lexical errors, in an EFL context, involving larger student populations. More studies comparing the findings of lexical errors in an EFL context, with the findings of lexical errors in an ESL context could also be conducted.

\section{Acknowledgments}

My thanks go to the reviewers for their insightful comments and suggestions that contributed to the development of this study. I would also like to thank my undergraduate students for their cooperation.

\section{References}

Al-Shormani, M., \& Al-Sohbani, Y. (2012). Semantic errors committed by Yemeni university learners: Classifications and Sources. International Journal of English Linguistics, 2(6), 120-139. https://doi.org/ 10.5539/ijel.v2n6p120

Basir, A., \& Zaiyadi. (2015). Lexical Errors in English for academic purposes (EAP) students'essays. Proceeding of the 2nd International Conference on Management and Muamalah.

Carter, R. (1998). Vocabulary: Applied linguistics perspectives. London: Routledge. https://doi.org/10.4324/978 0203270110

Folse, K. (2004). Myths about teaching and learning second language vocabulary: What research says. TESL Reporter, 37(2), 1-13.

James, C. (1998). Errors in language learning and use: Exploring error analysis. Harlow: Longman.

Hamadi. (2016). An analysis of lexical errors in the English compositions of EFL Tunisian learners. International Journal of Humanities and cultural studies, 2(4), 643-652.

Hemchua, S., \& Schmitt, N. (2006). An analysis of lexical errors in the English compositions of Thai learners. Prospect, 21(3), 3-25.

Leech, G. (1981). Semantics (2nd Ed.).Middlesex: Penguin Books.

Rajab, A., Darus, S., \& Aladdin, A. (2016). An investigation of semantic international errors in the writing of Libyan English as foreign language learners. Arab World English Journal, 7(4), 277-296. https://doi.org/ 10.24093/awej/vol7no4.18 
Schmitt, N. (2000). Vocabulary in language teaching. Cambridge: Cambridge University Press.

Shalaby, N., Yahya, N., \& El-Komi, M. (2009) Analysis of lexical errors in Saudi college students' compositions. Ayn, Journal of the Saudi Association of Languages and Translation, 2(3), 65-93.

\section{Copyrights}

Copyright for this article is retained by the author(s), with first publication rights granted to the journal.

This is an open-access article distributed under the terms and conditions of the Creative Commons Attribution license (http://creativecommons.org/licenses/by/4.0/). 